\title{
DETECTION \& PREVALENCE OF EXTENDED SPECTRUM BETA - LACTAMASES AMONG ENTEROBACTERIACEAE SPECIES FROM VARIOUS CLINICAL SAMPLES AT KIMS, AMALAPURAM.
}

\author{
N. Padmaja, Anand Acharya, P. Nageswar Rao
}

1. Assistant Professor, Department of Microbiology, Konaseema Institute of Medical Science, Amalapuram, Andhra Pradesh.

2. Associate Professor, Department of Pharmacology, Konaseema Institute of Medical Science, Amalapuram, Andhra Pradesh.

3. Professor \& Head, Department of Microbiology, Konaseema Institute of Medical Science, Amalapuram, Andhra Pradesh.

\section{CORRESPONDING AUTHOR}

Dr. Anand Acharya,

KIMS Hospital, Amalapuram,

Andhra Pradesh.

E-mail: anand_kims@yahoo.co.in,

Ph: 009109963598050.

ABSTRACT: The present study was conducted in the Department of Microbiology, KIMS, Amalapuram, East Godavari from January 2012 to July 2012. Out of 100 different clinical samples, 50 were culture positive. Of the 100 samples collected, more were from post operative wound sepsis - 44 (44\%), followed by cellulites - 20 (20\%), Ulcers - 17 (17\%), Injuries 15 (15\%). Least number of cases are from burns - 4 (4\%). Among 50 culture positive cases, 38 $(76 \%)$ isolates belonged to Enterobacteriaceae family, followed by Pseudomonas aeruginosa - 8 (16\%), followed by Staphylococcus aureus - 4 (8\%). Among 38 of Enterobacteriaceae family isolates, 15 were ESBL producers. Among ESBL positive strains, more drug resistance was seen to Ceftazidime and Ampicillin (93.33\%), followed by Ceftriaxone (86.66\%), Aztreonam \& Cefotaxime (80\%).

INTRODUCTION: Hospital outbreaks of multi-drug resistant Enterobacteriaceae are now frequently caused by extended spectrum beta-lactamase (ESBL) producers. The incidence of ESBL producing strains among clinical isolates has been steadily increasing over past years resulting in limitation of therapeutic options.

$\beta$ - lactamase antibiotics are the most varied and widely used agents accounting for over $50 \%$ of all systemic antibiotics in use. The most common mode of acquisition of bacterial resistance to $\beta$ - lactam antibiotics is the production of $\beta$ - lactamase. However, new $\beta$ lactamases emerged against each of the new classes of $\beta$ - lactamase that were introduced \& caused resistance. The latest in the arsenal of these enzymes has been evolution of extended spectrum $\beta$ - lactamases (ESBLs). These enzymes are commonly produced by many members of Enterobacteriaceae and efficiently hydrolyze oxyimino cephalosporins conferring resistance to $3^{\text {rd }}$ generation cephalosporins like Cefotaxime, Ceftazidime \& Ceftriaxone 4 .

ESBLs pose a major problem for clinicians. Hence, this study is taken to identify the prevalence of these strains in hospital \& to determine suitable preventive measures \& treatment policies. 
MATERIALS \& METHODS: Different clinical samples collected from both inpatients \& outpatients of KIMS Hospital, Amalapuram, during January 2012 - July 2012, constitute the material for this study.

A total of 38 Enterobacteriaceae species were isolated from 100 pus samples of different diseases including both sexes and all age groups.

MATERIALS REQUIRED: Specimens were inoculated on to the media - Mac Conkey, Blood agar and incubated at $37^{\circ} \mathrm{C}$ for 18 - $24 \mathrm{hr}$ and identified by Gram's stain, culture, biochemical tests and Antibiotic sensitivity test. For detection of ESBL, ESBL E Strip test is used.

METHOD: E-TEST ESBL SCREEN: (CORMICAN ETAL 1996) ${ }^{14}$ : The strip carries two antibiotic gradients Ceftazidime $(0.5-35 \mu \mathrm{g} / \mathrm{ml})$ and Ceftazidime with Clavulanic acid $(0.064-4 \mu \mathrm{g} / \mathrm{ml})$. The E test method was carried out according to manufactures instructions.

Colonies from 18-24 hrs. cultures were emulsified in sterile normal saline, incubated for 4 to $6 \mathrm{hrs}$. to an inoculum turbidity equivalent to 0.5 Mc Farland standard. This suspension was swabbed over on to Muller hinton agar plate and it is allowed to dry for 10 - 15 mins at room temperature. An ESBL E strip was then applied to plate with sterile forceps and the plate was incubated at $370 \mathrm{C}$ for $18 \mathrm{hrs}$. After incubation, the MICs were read according to the manufacturers guidelines and the ratio determined. (The MIC ratio $\geq 8$ indicates ESBL production. It is considered Gold standard. ${ }^{15}$

INTERPRETATION OF TEST RESULT: The MIC value was read where the elliptical zone of growth inhibition intersected the E test strip. The MIC of Ceftazidime alone on one end of strip was compared with the MIC of Ceftazidime + Clavulanic acid combination at other end. A greater than fourfold reduction in the Ceftazidime MIC in the presence of Clavulanic acid was taken as positive for ESBL production ${ }^{10}$.

For ESBL screening, the antibiotic discs used are Ceftazidime, Cefotaxime, Ceftriaxone, Aztreonam, Amoxycillin+Clavulanic acid, Ceftazidime+Clavulanic acid, Cefotaxime+Clavulanic acid and Imipenem. The incubated plates were read for zone of inhibition and results are interpreted comparing with the standard zone size given by Kirby-Bauer chart ${ }^{9}$

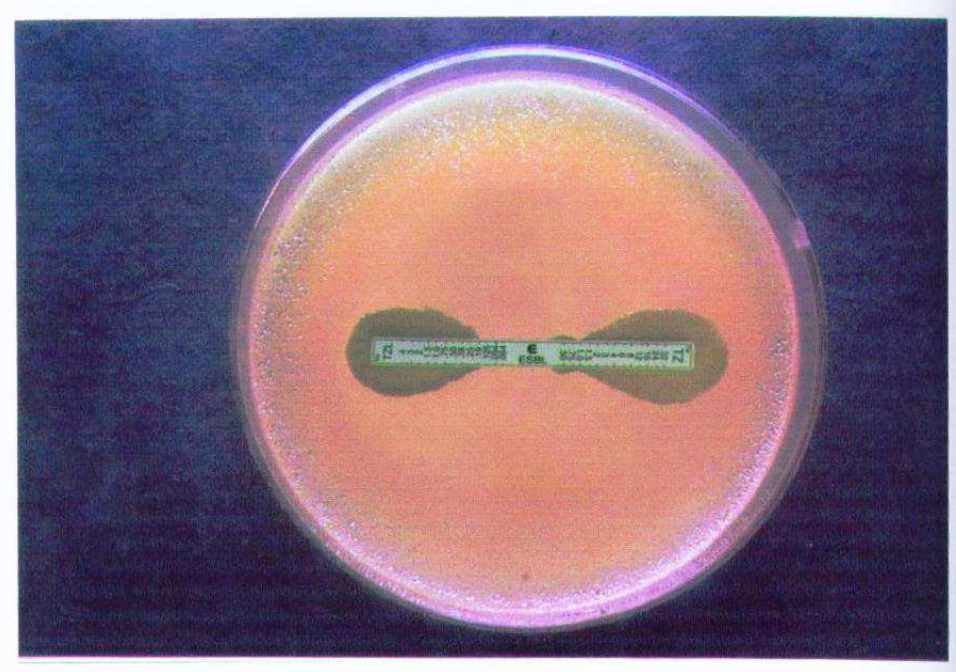

E STRIP TEST FOR ESBL PRODUCTION

Journal of Evolution of Medical and Dental Sciences/Volume1/ Issue4/October-2012 Page 401 


\section{QUALITY CONTROL:}

Escherichia coli ATCC 25922 - Used as negative control.

In house ESBL producers are used as positive control.

\section{RESULTS:}

Out of 100 samples collected, high number of cases are from males $70(70 \%)$ and low number of cases are from females $30(30 \%)$.

\begin{tabular}{|l|l|l|l|}
\hline S.No & Sex & No. Of Cases & $\%$ \\
\hline 1 & Males & 70 & $70 \%$ \\
\hline 2 & Females & 30 & $30 \%$ \\
\hline
\end{tabular}

Among 100 sample collected, more were from post-operative wound sepsis - 44(44\%), followed by Cellulitis - 20 (20\%), Ulcer - 17 (17\%), Injuries 15 (15\%), Burns 4 (4\%).

\begin{tabular}{|l|l|l|}
\hline S.No & Disease & No. of Samples \\
\hline 1 & Post operative wounds & 44 \\
\hline 2 & Cellulitis & 20 \\
\hline 3 & Ulcer & 17 \\
\hline 4 & Injuries & 15 \\
\hline 5 & Burns & 4 \\
\hline
\end{tabular}

Of the 100 samples processed, 50 were culture positive. Of these, 38 (76\%), isolates belonged to Enterobacteriaceae family, followed by Pseudomonas aeruginosa 8 (16\%), followed by Staphylococcus aureus - 4 (8\%).

Table: 3 Different types of Bacterial species isolated

\begin{tabular}{|l|l|l|l|}
\hline S.No. & Bacterial Species & $\begin{array}{l}\text { Culture Positive } \\
\text { cases }\end{array}$ & Percentage \\
\hline 1 & Escherichia coli & 21 & $42 \%$ \\
\hline 2 & Klebsiella pneumonia & 9 & $18 \%$ \\
\hline 3 & Proteus mirabilis & 4 & $8 \%$ \\
\hline 4 & Citrobacter spp & 2 & $4 \%$ \\
\hline 5 & Proteus vulgaris & 2 & $4 \%$ \\
\hline 6 & Pseudomonas aeruginosa & 8 & $16 \%$ \\
\hline 7 & Staphylococcus aureus & 4 & $8 \%$ \\
\hline
\end{tabular}

Of the 38 Enterobacteriaceae isolates, 15 are ESBL producers. 
Table 4: Distribution of Bacteria producing ESBLs

\begin{tabular}{|l|l|l|l|l|}
\hline S.No & Bacterial Species & Total isolates & $\begin{array}{l}\text { ESBL } \\
\text { Producers No. }\end{array}$ & $\%$ \\
\hline 1 & Escherichia coli & 21 & 8 & $38 \%$ \\
\hline 2 & Klebsiella pneumoniae & 9 & 5 & $55.5 \%$ \\
\hline 3 & Proteus mirabilis & 4 & 1 & $25 \%$ \\
\hline 4 & Citrobacter spp & 2 & 1 & $50 \%$ \\
\hline 5 & Proteus vulgaris & 2 & 0 & - \\
\hline
\end{tabular}

(Note: Percentage of ESBL producers calculated as per the respective total isolates)

Among ESBL positive strains, more drug resistance was seen to Ceftazidime and Ampicillin (93.33\%), followed Ceftriaxone (86.66\%) Aztreonam \& Cefotaxime (80 \%). All ESBL producers showed full sensitivity to Imipenem.

Table 5: Comparison of Antimicrobial Resistance pattern of ESBL producers \& Non ESBL producers.

\begin{tabular}{|l|l|l|l|l|l|l|}
\hline & & \multicolumn{2}{|c|}{} & \multicolumn{2}{|c|}{} \\
S.No & Drugs & \multicolumn{2}{|c|}{ I ESBL Positive (15) } & \multicolumn{2}{|c|}{ ESBL Negative (23) } \\
\hline 1 & Ampicillin & 14 & $93.33 \%$ & 10 & $43.47 \%$ \\
\hline 2 & Gentamicin & 3 & $20 \%$ & 9 & $39.13 \%$ \\
\hline 3 & Amikacin & 4 & $26.66 \%$ & 4 & $17.39 \%$ \\
\hline 4 & Ciprofloxacin & 4 & $26.66 \%$ & 3 & $13.04 \%$ \\
\hline 5 & Chloramphenicol & 5 & $33.33 \%$ & 4 & $17.39 \%$ \\
\hline 6 & Co - trimoxazole & 7 & $46.66 \%$ & 12 & $52.17 \%$ \\
\hline 7 & Aztreonam & 12 & $80 \%$ & 8 & $34.78 \%$ \\
\hline 8 & Cefotaxime & 12 & $80 \%$ & 2 & $8.69 \%$ \\
\hline 9 & Ceftazidime & 14 & $93.33 \%$ & 3 & $13.04 \%$ \\
\hline 10 & Ceftriaxone & 13 & $86.66 \%$ & 3 & $13.04 \%$ \\
\hline 11 & Imipenem & 0 & 0 & 0 & 0 \\
\hline
\end{tabular}

(Note: Percentage of positive and negative ESBL drug resistance pattern calculated as per respective antibiotics tested).

DISCUSSION: ESBLs are the main cause of resistance to beta lactam antibiotics in Enterobacteriaceae. As their occurrence has been increasing it becomes essential to evaluate their occurrence in population

The present study was undertaken to evaluate the pattern of drug resistance produced by isolates of Enterobacteriaceae family causing various diseases especially in hospitalized patients and to known the prevalence of ESBL production.

In the present study, out of 100 pus samples, rate of recovery of isolates belonging to Enterobacteriaceae family is 38 . i.e. $76 \%$. In this study, males $(70 \%)$ are more commonly affected than females (30\%) due to the fact that males are more involved in out door activities \& hence chances of infection or injury are more likely. 
An outbreak of nosocomial infection due to ESBL isolates of Enterobacteriaceae family occur worldwide in intensive care units as shown by different workers, Yagi et al 2000, Silver et al 20014,6,12. Risk factors associated with ESBL production include - prolonged hospital or intensive care stay, use of multiple courses of antimicrobial therapy, particularly extended spectrum cephalosporins. In the present study, ESBL production is more in Cellulitis cases due to prolonged hospital stay \& indiscriminate use of multiple courses of antibiotics. Hence indiscriminate use of cephalosporins and broad spectrum antibiotics should be avoided.

\section{CONCLUSION:}

ESBL isolates of Enterobacteriaceae family is major problem world wide. In discriminate use of third generation cephalosporins to treat gram negative bacterial infection is partly responsible for the emergence of resistance to beta - lactam antibiotics. Strict adherence to the hospital antibiotic policy and good infection control practices can play a significant role in reducing the emerging drug resistance

\section{REFERENCES:}

1. A. Varaiya, J. Dogra, M. Kulkarni, P. Bhalekar - " Extended spectrum Beta lactamase (ESBL) producing Escherichia coli and Klebsiella pneumoniae in Diabetic foot infection Department of Microbiology ", S.L. Raheja Hospital, Mahim West, Mumbai - 400016, IJMM, India - 7th August 2008.

2. Subha, S. Ananthan - " Extended spectrum Betalactamase (ESBL) Mediated Resistance to Third Generation Cephalosporins among Klebsiella pneumoniae in Chennai " - Indian Journal of Medical Microbiology, (2002) 20 (2) ; 92-95.

3. A.A. Dashit, P. West, R. Paton and S.G.B. Amyes - Characterization of extended-spectrum Beta-Lactamase (ESBL) - Producing Kuwait and UK strains identified by the Vitek system, and sub sequent comparison of the Vitek system, with other commercial ESBL Testing systems using these strains" - Molecular Chemotherapy, Centre for Infectious Disease - January 2006.

4. Amit Jain \& Rajesh Mondal - "Prevalence and antimicrobial resistance of extended spectrum Beta-Lactamase producing Klebsiella spp. isolated from cases of neonatal septicemia" - Indian J Med. Res, January 2007, PP 89-94.

5. Ankur Goyal, Amit Prasd, Ujjala Ghosal \& K.N. Prasad - "Comparison of disk diffusion, disk potentation \& double disk synergy methods for detection of extended spectrum beta lactamase in Enterobacteriaceae" - Indian Journal Med Res. 128, August 2008, PP 209-211.

6. Ashwin N Ananthakrishnan, Reba Kanungo, A. Kumar and S. Badrinath - "Detection of extended spectrum Beta-lactamase producers among surgical, wound infections and Burns patients in jipmer" - Indian Journal of Medical Microbiology (2000) 18 (4) : 160165.

7. Bisson, G.Fishman, N.O. Patel, J.B.; Edel Stein, P.H ; Lautenbanch,E. " Extended-spectrum beta-lactamase-producing Escherichia coli and Klebseilla species; risk factors for colonization and impact of antimicrobial formulary interventions on colonization", Prevalence, Infection and control, Thorofare, v.23, p.254-260,2002. 
8. C. Rodrigues, P Joshi, SH Jain, M Alphonse, R. Radhakrishnan, "A Metal-detection of Betalactamases in Nosocomial Gram Negative Clinical Isolates"- Indian Journal of Medical Microbiology, (2004) 22 (4) : 247-250.

9. Colonder, R.; Raz, R.; Chazan, B.; akran, W. "Susceptibility pattern of extended-spectrum Beta-lactamase producing bacteria isolated from inpatients to five antimicrobial drugs in community hospital in Northern Israel", International Journal of Antimicrobial Agents, Shannon, v. 24, p. 409-410,2004.

10. Cormican MG, Marshall SA, Jones RN. "Detection of spectrum $\beta$-lactamases (ESBL) producing strains by E-test ESBL screen" J. Clin Microbiol 1996: 1880-84.

11. MS Kumar, V. Lakshmi, R. Rajagopalam "Occurance of extended spectrum BetaLactamases among Enterobacteriaceae SPP isolated at a Tertiary care institute" - Indian Journal of Medical Microbiology (2006) 24 (3) : 208-11.

12. Yagi, T.; Kurokawa, H.; Shibata, N.; Shibayama, K.; Arakawa, Y. "A Preliminary survey of extended-spectrum Beta-lactamases (ESBLs) in clinical isolates of Klebsiella pneumoniae and Escherichia coli". FEMS Microbiology Letters, Amsterdan, v.184, p.53,2000.

13. Silva, J.; Gatica, R.; Aguilar, C.; Becerra, Z.; Ramos, U.G.; Velazquez, M.; Miranda, G.; Leanos, B.; Solorzano, F.. Echaniz, G. "Outbreak of infection with extended-spectrum Beta-lactamase producing Klebsiella pneumoniae in a Mexican hospital". Journal of Clinical Microbiology, Washington, V.39, p. 3193-3193, 2001.

14. 1996 Aug;34(8):1880-4. Detection of extended-spectrum beta-lactamase (ESBL)producing strains by the Etest ESBL screen. Cormican MG, Marshall SA, Jones RN

15. Determination of minimal inhibitory concentration Jinnifer M. Andrews journal of antimicrobial chemotherapy(2001) 48 suppl.s1,5-16. 